\title{
Propaganda del odio: las exposiciones anticomunistas en el Tercer Reich ${ }^{1 *}$
}

\author{
Antonio César Moreno CANTANO \\ Universidad de Alcalá \\ antoniomorenocantano@hotmail.com \\ Misael Arturo LóPEZ ZAPICO \\ UNED. Centro asociado de Asturias \\ artzapico@yahoo.es
}

Recibido: 23 de julio de 2014

Aceptado: 17 de septiembre de 2014

\section{Resumen}

El dominio y control de las masas es imprescindible para el soporte de cualquier Estado. El Tercer Reich fue consciente, desde muy temprana hora, de la necesidad de crear en el ideario colectivo un enemigo común que le sirviese como elemento cohesionador de la sociedad y aglutinador de descontentos, y ese no fue otro que el colectivo judeo-comunista. Con ese fin se desplegaron por toda Alemania durante los años 30 diversas exposiciones de propaganda negativa de carácter anticomunista y antisemita. En el presente artículo analizaremos el funcionamiento de las mismas desde un punto de vista cultural y político, recurriendo a abundante bibliografía alemana y fuentes archivísticas españolas.

Palabras clave: Propaganda; Enemigo; Anticomunismo; Odio; Antisemitismo; Conspiración mundial.

\section{Hate Propaganda: the Anti-communists Exhibitions in the Third Reich}

\begin{abstract}
The control of the masses is essential for the support of any nation. The Third Reich was soon aware of the need to create a common enemy in the collective ideology that could be used to bring together the popular discontent and would also serve as society's unifying force. That enemy was no other than the so called Jewish Bolshevism. To achieve that goal, the Nazi authorities organized during the thirties several exhibitions all across Germany with an obvious anti-communist and anti-semitic message. In this paper, we will analyze these exhibitions under a cultural and political approach resorting to the extensive German literature and Spanish archival sources.
\end{abstract}

Key words: Propaganda; Enemy; Anti-communism; Hate; Antisemitism; World Conspiracy.

\section{Referencia normalizada}

Moreno Cantano, A. C. y López Zapico, M. A. (2014). Propaganda del odio: las exposiciones anticomunistas en el Tercer Reich. Historia y Comunicación Social. Vol. 19. Páginas 171-192.

Sumario: 1. Introducción: odio y miedo como ejes del análisis histórico. 2. Exposiciones de propaganda negativa. 3. Exposiciones positivas: modernidad y progreso en el Tercer Reich. 4. Conclusiones. 5. Referencias bibliográficas. 


\section{Introducción: odio y miedo como ejes del análisis histórico}

Como se argumentó desde el ámbito de la Psicología -por ejemplo, McDougall en su obra The Group Mind (1920)-, ya a principios del siglo XX, uno de los fenómenos más singulares e importantes de la formación de las masas consistía en la exaltación e intensificación de la emotividad de los individuos que la integran. Conscientes de estas ideas, las exposiciones nazis estaban proyectadas a una colectividad que se sobreentendía como excitable, impulsiva, apasionada, versátil, inconsecuente, indecisa, accesible a las pasiones violentas y a los sentimientos elementales, fácil de sugestionar, etc. (Freud, 1991: 22-25). En los últimos años se ha orientado el estudio de la cultura visual bélica atendiendo a todos los condicionantes recién esbozados. Paradigmático e innovador, en este sentido, es el trabajo colectivo de Berthier y Sánchez Biosca (2012), cuyo eje de análisis se basa en el concepto de miedo. En directa relación con este ha de situarse un instinto más primario, el odio, el cual ha estado presente en todo tipo de eventos propagandísticos. Pionero en este campo y en su aplicación al ámbito del Arte y la Psicología ha sido el profesor Robert J. Sternberg (2005). A la hora de profundizar en este sentimiento, señal identificativa de las masas, Sternberg distingue tres conceptos interrelacionados entre sí que estuvieron muy presentes en las exposiciones anticomunistas celebradas en la Europa del Eje: negación de la intimidad, pasión y compromiso (Sternberg y Sternberg, 2008: 51-109).

Siguiendo este diseño, el primer componente esencial del odio es, entonces, la negación de la intimidad o distanciamiento. El mismo implica la distancia emocional hacia el otro, quien es observado con repulsión y asco, incluso sin necesidad de que exista un contacto directo. La propaganda se encarga posteriormente de dar a conocer y denunciar la "repugnancia" de un individuo concreto, asimilado a una cultura o pueblo, como por ejemplo los judíos. Todas sus supuestas cualidades negativas se englobaban en un estereotipo conjunto de carácter negativo que los retrataba en la prensa, la pintura, el cine, como enloquecidos, codiciosos o excepcionalmente feos (Sternberg y Sternberg, 2008: 59-62).

El segundo factor del odio es la pasión que se expresa como una intensa ira o miedo en respuesta a una amenaza (Sternberg y Sternberg, 2008: 62-65). Es tarea de la propaganda, escrita o visual, intensificar este peligro para acrecentar el odio hacia el otro. Obras como Los Protocolos de los Sabios de Sión (1920), Notes sur la révolution bolchevique (Sadoul, 1920) o Das Rotbuch über Spanien (1937) son solo una pequeña muestra de esta literatura del miedo y del complot judeo-bolchevique que "amenazaba" las señas de identidad de Alemania, España y Francia.

La tercera premisa expuesta por Sternberg es la devaluación del otro a través del desprecio que conduce al compromiso del individuo hacia la confrontación. Proceso inexorablemente unido a un programa educacional de la población o de "lavado de cerebro". Durante el Holocausto, por ejemplo, los nazis tomaron el control del sistema educativo y reconstruyeron la Historia según sus intereses ideológicos, presentando a los judíos como eternos opresores a los que no cabía dar otra respuesta que el odio (2008: 65-71). El contrario, siguiendo las tesis de Sternberg, adoptaba incon- 
tables formas y caracterizaciones. Se le presentaba como extraño, enemigo de Dios, bárbaro, criminal, torturador, secuestrador, conspirador... (2008: 84).

¿Por qué usar el odio como elemento vertebrador de la propaganda? Aunque cada caso a estudiar presenta particularidades propias, podemos fijar una serie de objetivos generales: 1) puro fanatismo; 2) los dictadores defienden un programa ideológico negativo que únicamente encuentra su razón de ser en principios basados en el miedo y en el mal; 3) la necesidad de poder y control sobre los demás; 4) la búsqueda de recursos, volcando el odio contra un grupo o país para justificar la apropiación de sus riquezas, territorio, etc. y 5) la cohesión interna de la sociedad mediante la agresión a un imaginario o real enemigo exterior.

¿Y cómo participaba el Arte en todo este proceso? El historiador británico Eric Hobsbawm nos enumeraba los siguientes servicios. El primero es demostrar la gloria y triunfo del poder. Para ello se recurre a la pompa y gigantismo de sus construcciones y realizaciones artísticas. Seguidamente, se nombra su protagonismo en el proceso de ritualización y organización de la sociedad. Se pretende estimular el patriotismo de las masas mediante el diseño de amplios espacios para ceremonias especiales, como podían ser las Exposiciones Internacionales. El tercer servicio era, y es, utilizar el Arte como un factor más dentro del campo educativo: enseñar, inculcar e informar del sistema de valores del Estado (Hobsbawm. 1995: 12-13).

Nuestra intención es profundizar en estas cuestiones desde diferentes planos metodológicos. En primer lugar, aproximarnos al contexto político y bélico en el que se gestaron. Otro foco girará en torno a la expresión artística de dichas "conmemoraciones", desde la perspectiva del giro de imagen, es decir, considerando el material visual empleado en ellas como un elemento generador de cultura por sí mismo (Hurtado Lamas, 2013). Como defiende excelentemente Peter Burke, es necesario acabar con la invisibilidad de lo visual, reivindicando el uso de la imagen como documento histórico (2001: 12-16). Y finalmente, la plasmación física de estas iniciativas propagandísticas en forma de folletos. Todo ello dentro de los presupuestos de una corriente en boga como es la historia de las emociones (Zaragoza Bernal, 2013), en la que podemos destacar nombres como los de Barbara H. Rosenwein (2010) o William M. Reddy (2001).

¿Qué acogida tuvieron entre el gran público este tipo de eventos? ¿Cuáles eran sus objetivos? ¿Los cumplieron? A lo largo de las siguientes páginas se dará respuesta a esas y otras muchas cuestiones, recurriendo para ello a la literatura especializada al uso, así como a diversas fuentes archivísticas y hemerográficas. Una compleja tarea que requiere desentrañar la conexión existente entre los tres elementos que determinan el funcionamiento de estas exposiciones: Política -en este caso, anticomunismo y guerra-, Arte -tradición frente a vanguardia- y Propaganda. 


\section{Exposiciones de propaganda negativa}

A partir de 1936, con la gradual radicalización de la política nazi -mayor agresividad en política exterior, incremento del Estado de terror, reorganización del Gobierno y del Ejército (Evans, 2005)-, Joseph Goebbels abandonó sus concomitancias con el modernismo y pasó a ser uno de sus más efectivos hostigadores. La celebración de los Juegos Olímpicos en Berlín supuso un paréntesis de paz y tranquilidad dentro de la, cada vez más excluyente, política cultural y racial nazi (Welch, 2002). Con su finalización toda la ira del Reich se desató y comenzaron a organizarse, por todo el país, numerosas exposiciones de propaganda contra el bolchevismo, el judaísmo -interpretados ambos como un mismo cuerpo-, y el arte modernista, al que se veía como un pernicioso producto de los anteriores.

En el mitin del NSDAP de septiembre de 1936, Hitler dijo que el objetivo del bolchevismo, creado y dirigido por los judíos, era "exterminar" y destruir la cultura de los Estados europeos. Una vez cumplido este objetivo, "sería seguido por el establecimiento de un Judaísmo internacional que dominaría Europa" (Herf, 2006: 42-43). Atendiendo a estas premisas, se desplegaron por todo el país una serie de eventos propagandísticos cuya finalidad principal era recordar a la población los defectos y peligros que entrañaba para la sociedad germana el judío, arquetipo inexorablemente ligado al comunismo internacional. Mediante paneles, carteles, fotomontajes y otros elementos visuales, estas exposiciones tuvieron como principal meta fomentar el odio hacia estos grupos y lograr la adhesión a las tesis nazis recurriendo para ello a un discurso fundamentado en el miedo.

\subsection{Weltfeind Nr. 1 - Der Bolschewismus (El Enemigo No 1 - El Bolchevismo)}

La muestra fue impulsada por el Reichsministerium für Volksaufklärung und Propaganda bajo la dirección de Goebbels e inició su andadura en Núremberg el 8 de septiembre de 1936 para concluir el 30 de mayo de 1937, tras parar en ciudades como Ingolstadt, Augsburg, Ulm, Karlsruhe, Frankfurt am Main, Mainz o Hamburgo. Se trataba de un convoy formado por diferentes vagones que recorrió gran parte de Alemania. El fundamento de la misma era la exposición de imágenes negativas y estereotipadas de los judíos, con el fin de vincular la propaganda política y racista entre sí. La entrada permitía, además, visualizar un breve documental en el que, junto a las estampas que aparecían en los vagones o remolques, se retrataban escenas desgarradoras y dramas sobre el peligro bolchevique en España y el resto del mundo. Se ponía el acento en la burla a Dios y a la religión, así como en los asesinatos perpetrados por la Policía Secreta Soviética, la temida GPU (Kivelitz, 1999: 214-216). Al poco tiempo de su finalización apareció un folleto sobre este evento que recopilaba el material expuesto y que fue elaborado por Friedrich Richter, doctor en Derecho y Presidente del Movimiento Cristiano Alemán, Bund Freikirchlicher Christen. 
Imagen 1 y 2. Sendas imágenes sobre la Exposición Der Welfeind Nr.1
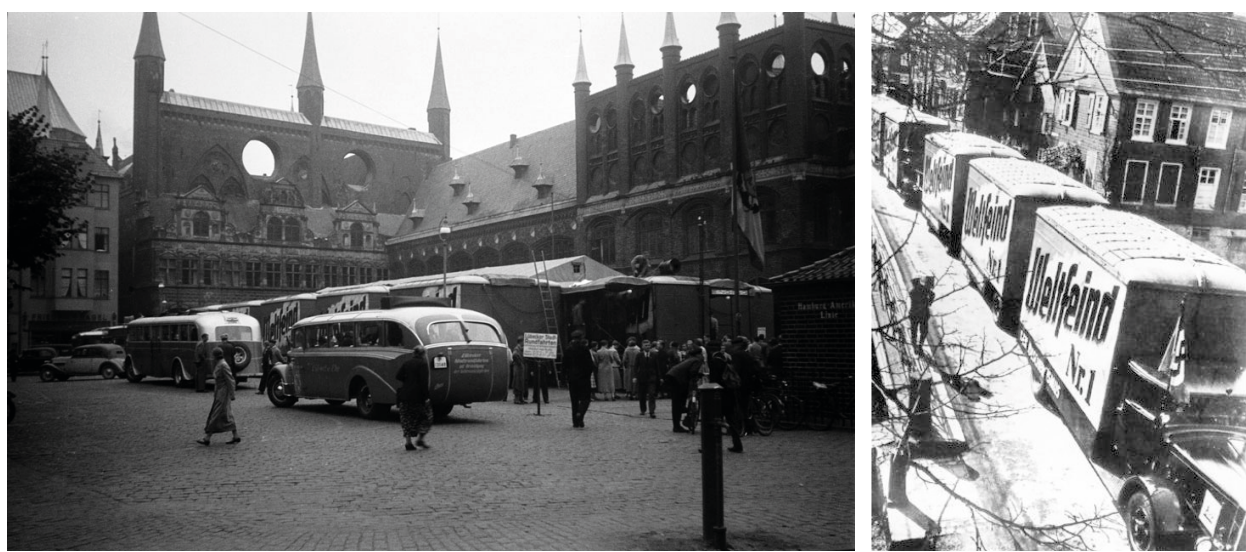

Fuente: Kivelitz, 1999

\subsection{Große antibolschewistische Schau (Gran Exposición Antibolchevique)}

Ni dos meses después del inicio de la anterior exposición se celebraba en la capital de Baviera, de noviembre de 1936 a enero de 1937 la Große antibolschewistische Schau la cual, posteriormente, fue también exhibida en Dortmund, Karlsruhe, Mannheim o Stuttgart (Eskilsson, 2009: 116-118). Instalada en la biblioteca del Deutsches Museum de Múnich, estuvo dirigida por Walter Wüster ${ }^{2}$. A ella asistieron representantes y artistas extranjeros, entre los que sobresalen el arquitecto italiano Cesare Ligini o el húngaro Gusztáv Baranyai-Lörincz. A su vez, por parte germana destacan reconocidas personalidades como el arquitecto Fritz Von Valtier o el diseñador gráfico Horst Schlüter, autor del cártel de la exposición El Judio eterno. Cabe destacar que el de este acto propagandístico fue elaborado por Max Eschle y que el tema escogido fue un gran brazo esquelético de color rojo, asimilándolo a la sangre, que agarraba un enorme cirio - no es casualidad su inclinación hacia abajo, en un claro signo de ateismo- y prendía fuego a la catedral de Múnich.

Inspirada en la Mostra Della Rivoluzione Fascista (1932-1934), el espectador que accedía al Museo de Múnich encontraba una antesala apenas iluminada, a modo de preámbulo, donde los focos se concentraban en una corona de roble dedicada a la memoria de los fusilados tras el Putsch de 1923. La pared principal estaba decorada con un fragmento de la canción de Horst Wessel, a la sazón convertido en el himno nazi, en enormes letras de estilo gótico: Kamraden Die Rotfront Und Reaktion Erschossen (Camaradas muertos por el Frente Rojo y la Reacción). Seguidamente, se accedía a otros habitáculos con abundantes fotomontajes y carteles donde aparecían llamativas contraposiciones sobre la "verdadera" faz del bolchevismo. Uno de estos montajes, que recordaban a los creados por el caricaturista John Heartfield a favor 
del bando republicano durante la Guerra Civil Española (Mayor Ferrándiz, 2011), retrataba a Stalin rodeado de alegres y animados niños (Stalin und die Kinder), y a su lado, para "desvelar" la falsedad de tal situación, aparecía una mujer con su hijo desnudo, esquelético, con una expresión de horror y desolación.

Imagen 3. Uno de los más impresionantes fotomontajes de la exposición Große antibolschewistische Schau

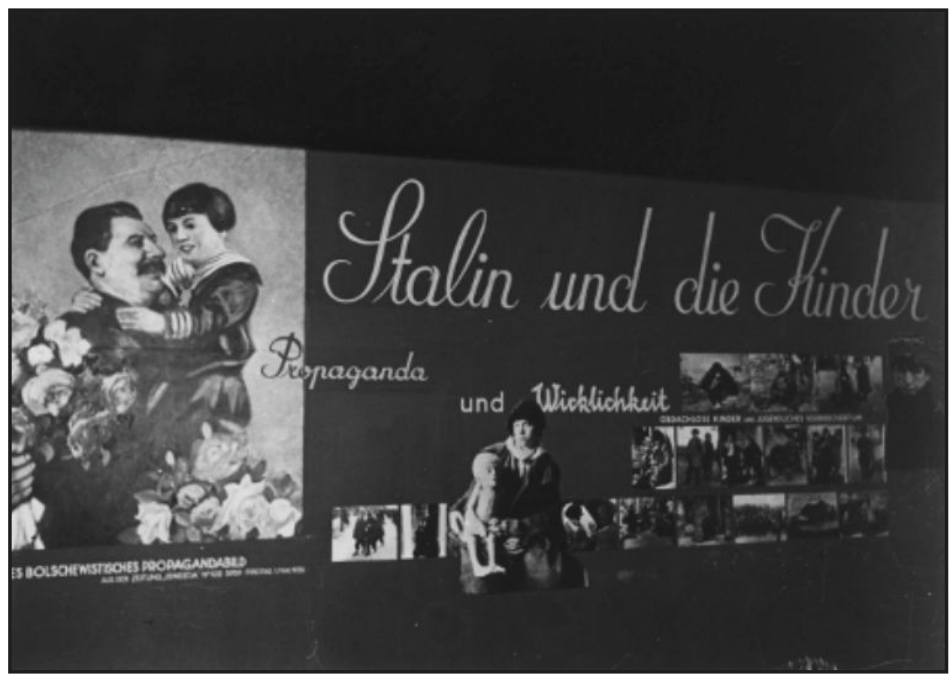

Fuente: Schuster, 1988

Mucho de este material había sido recopilado por el Antikomintern y había ilustrado obras sobre el peligro "rojo" en la contienda bélica española. Era el caso de títulos como Das Rotbuch über Spanien (1937) o Christen im Spanischen Sturm (Baldauf, 1938), en los que abundaban fotografías de víctimas de la barbarie soviética ${ }^{3}$. En sintonía al contenido de estos dos folletos sobre la guerra en España, se decoraron las paredes con tapices que versaban sobre "la lucha contra el caos" y "la bestia que sube del abismo", en alusión al peligro bolchevique que amenazaba el futuro del pueblo germano (Große antibolschewistische Ausstellung, 1937).

Italia y Hungría también tuvieron una relevante representación en este evento. La primera recurrió a paneles sobre "el sacrificio de los mártires" -en referencia a los Camisas Negras-, retratos del Duce y reliquias del fascismo. La sección húngara ocupó un espacio menor y se centró en el "reinado de terror" de la época de Béla Kun. Su imagen se acompañó de una galería de fotos de los líderes judíos de Hungría en ese periodo y frente a ellos se posicionaba la figura del Almirante Miklós Horthy, "el Salvador". Tras atravesar estos espacios, se llegaba a una gran sala sobre la vida en el interior de la URSS, plena de representaciones gigantescas y grotescas de soldados del Ejército Rojo, de seres monstruosos -el más explícito era una araña esquelética 
que agarraba entre sus patas el globo terráqueo- que encarnaban simbólicamente la amenaza internacional judeo-bolchevique. Todas las escenas se iluminaban con una potente y brillante luz roja. Al final, "para despertar de la pesadilla de las fuerzas del Mal", se llegaba a un amplio habitáculo, "con una atmósfera clara y limpia", con murales sobre la reconstrucción del país, obra de artistas muniqueses -como Elk Eber, Martin-Amorbach, T.O. Müller-, de miembros de las SA, de la Wehrmacht y de la Juventud Alemana (Große antibolschewistische Ausstellung, 1937). El mensaje final de esta exposición, tanto desde un punto de vista doméstico como internacional, era rotundo: solo la Nueva Alemania, junto a sus aliados, podía hacer frente al creciente poder del bolchevismo (Kivelitz, 1999: 216-220).

\subsection{Bolschewismus ohne Maske (E1 Bolchevismo sin máscara)}

En septiembre de 1937 esta exposición se trasladó a Núremberg y, a partir de noviembre, a Berlín (prolongándose hasta enero de 1938), Hamburgo (marzo-abril de 1938) y Viena. En estas tres últimas ciudades fue presentada con el nombre de Bolschewismus ohne Maske. Su organización corrió a cargo de Waldemar Steinecker, arquitecto y responsable del Instituts für Deutsche Wirtschaftspropaganda (Instituto para la Cultura Alemana y Propaganda Económica).

En el cartel que se realizó para publicitar este acto se observaba un esqueleto con vestimenta soviética que sostenía un fusil con bayoneta en una mano y en la otra arrastraba una pesada ametralladora que se posaba desafiante sobre la esfera terrestre. Como en otras ocasiones, se buscaba transmitir la internacionalización del peligro comunista. Estaba rodeado por una llama, que denotaba su naturaleza infernal, y sobre el mapa de Europa relucía la estrella de David junto al martillo y la hoz, es decir, nuevamente la conexión judeo-bolchevique.

Imagen 4 y 5 . Posters de la exposición Bolschewismus ohne Maske
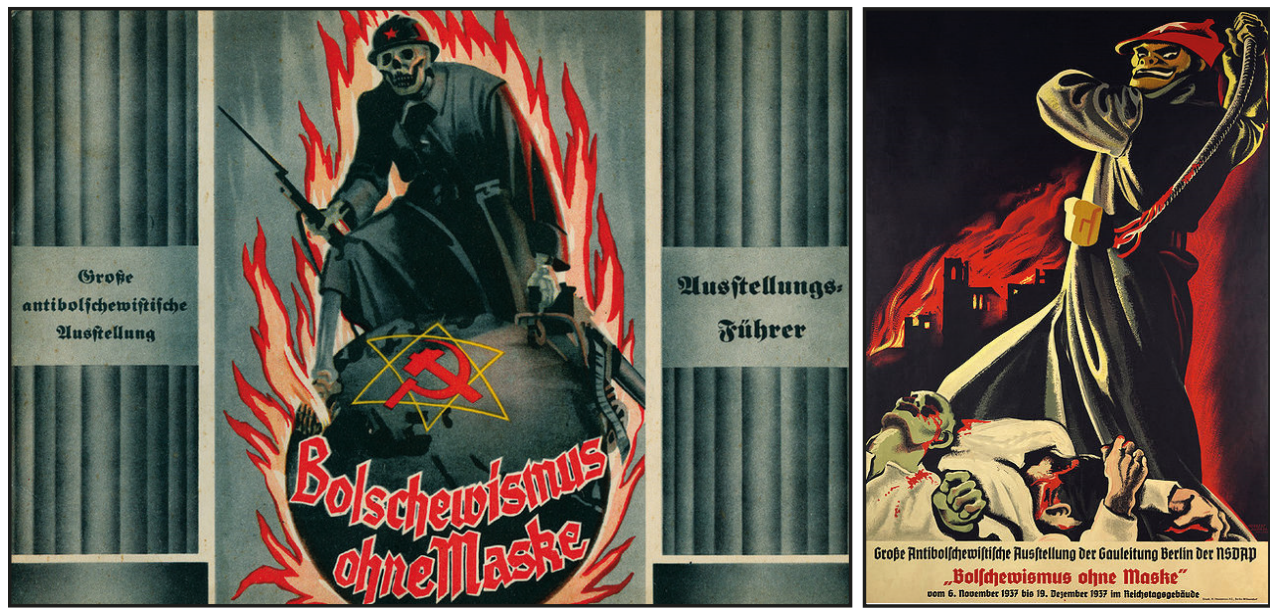

Fuente: Library of Congress, Prints and Photographs Division. Posters: Artist Posters. 
La Guerra Civil Española ocupó un lugar privilegiado. Como ya se había advertido en la obra Das Rotbuch über Spanien (1937), lo que se decidía en la Península Ibérica no era únicamente poner freno a la ingerencia rusa en los asuntos hispanos, sino evitar que este peligro se extendiese al propio corazón del Reich ${ }^{4}$. En el folleto que se editó como consecuencia de la celebración de esta exposición se dejaba bien latente la repercusión del conflicto español: "España es la encrucijada del mundo" (Große antibolschewistische Ausstellung, 1937). El propio discurso de Goebbels ese mismo año en Núremberg daba fe de la importancia de lo que estaba sucediendo en España. Publicado con el título de La Verdad sobre España (1937), apelaba a los conceptos e ideas que adquirieron forma visual en estas exposiciones propagandísticas: la conspiración judeo-bolchevique, el caos y la anarquía en la "zona roja" (Rotspanien), el riesgo de contagio del comunismo en caso de triunfar o la persecución religiosa. Para ilustrar visualmente y plasmar en palabras todos estos pensamientos se recurrió a los fondos del Archivo del Ministerio de Propaganda nazi así como los del Antikomintern, donde personal como Alfred Gielen ${ }^{5}$ y E.H. Bockhoff ${ }^{6}$ elaboraron todo un corpus teórico con el que alimentar los más intrincados y estrambóticos fotomontajes y paneles expositivos.

En esta exposición abundaron materiales compositivos de dicha índole (Williams, 2007). Uno de los paneles utilizados fue "la lucha en defensa de los pueblos contra la destrucción judía". El enemigo se personificaba bajo la forma de un gran pulpo, alegoría frecuentemente utilizada en la propaganda anticomunista y antisemita, que extendía sus tentáculos sobre el territorio alemán. Tan solo la sombra de un hercúleo cuerpo ario resistía este empuje. Otro panel, "La Dictadura de los Judíos", estaba compuesto por fotografías de líderes soviéticos como Stalin o Trotsky, así como de destacados banqueros alemanes de origen judío. En referencia al conflicto ibérico, se hallaba el panel "Danza de la muerte en España", con imágenes de iglesias destruidas, de esculturas religiosas amputadas o tumbas profanadas.

¿Tuvo el bando franquista alguna capacidad decisoria en la conformación de dicha propaganda? Aunque no tenemos información directa sobre el grado de participación española en este acto, otros datos indirectos nos pueden ayudar a dar una respuesta aproximada. En fechas cercanas, diciembre de 1937, el responsable de la Propaganda falangista en Berlín, Luis Sánchez Maspons, pedía material a sus jefes en la Península para la exposición que el Antikomintern pensaba realizar sobre la Guerra Civil. En este intercambio epistolar quedaba plasmada la carencia absoluta de medios para poder maniobrar libremente y organizarlo según sus propios intereses: "Respecto al decorado de la parte dedicada a Falange, como nosotros no disponemos de dinero, tendremos que pasar por lo que ellos quieran hacer..." otras muchas iniciativas propagandísticas exteriores de la España franquista, había una mayor voluntad que posibilidades reales de prosperar (Moreno Cantano, 2008). Sin embargo, y como ha quedado probado en diferentes estudios (Bowen, $2000 \mathrm{y}$ Rohr, 2007), estas ansias de mimetismo y colaboración entre elementos de Falange y del Tercer Reich tuvieron una gran fuerza y continuidad hasta mediados los años cuarenta. Un ejemplo curioso, y que encajaba con la línea ideológica que se promo- 
cionaba en las exposiciones hasta ahora analizadas, fue el de Nicolás Von Hortong. En ese verano de 1937, en pleno vigor propagandístico nazi contra el comunismo por todo el país, el camisa vieja de origen germano-ruso preguntaba al director del diario Unidad de San Sebastián si quería colaborar junto a él en la editorial antijudía y anticomunista U. Bodung-Verlag de Ulrich Fleischhauer. En concreto se refería a una posible participación falangista en la revista Service Mondial mediante el envío a Erfurt (Alemania) de material fotográfico sobre el conflicto peninsular. La petición de ayuda de Hortong era una clara muestra de la proximidad falangista hacia la tesis más radicales del Tercer Reich: "organizar debidamente la defensa periodística de nuestra querida España y luchar con armas adecuadas contra los rojos y sus adeptos, los judíos y los masones (la cloaca Internacional) [...] Dar una batalla decisiva a esta gentuza Judía y Masónica."

Para cerrar con el estudio de esta exposición anticomunista, cabe mencionar que otro de los paneles empleados contraponía la felicidad de los niños en la Alemania de Hitler con la miseria de los rusos, temática ya empleada en otras exhibiciones tal y como ha quedado de manifiesto. Para ello se utilizaba como modelo varias chicas de pelo rubio, fuertes, en actitud marcial, con ropa deportiva, y a sus pies -en menor tamaño- un círculo de jóvenes con el torso desnudo conversando animosamente, mientras que a la derecha de todo este fotomontaje los niños de la URSS aparecían mal vestidos, con harapos, delgados, con expresión famélica, en un espacio desolador y lúgubre (Kivelitz, 1999: 221-223).

A modo de resumen, los puntos vertebrales sobre los que gravitó el discurso empleado, y que, posteriormente, quedaron reflejados en el folleto de la muestra, fueron "el Bolchevismo alrededor del Mundo"; "El Judaísmo es la esencia del Bolchevismo"; "Marxismo y Bolchevismo pervierten a la Gente y a los Estados"; "El Marxismo destruye los lazos étnicos"; "Terror, Secuestro y Asesinato como herramientas de la revolución judeobolchevique internacional"; "La Rusia soviética: El Paraíso Soviético" - concepto que daría título a una nueva exposición celebrada en 1942-; "La Batalla y Victoria del Nacionalsocialismo" o "Italia combate contra el Bolchevismo" (Große antibolschewistische Ausstellung, 1937).

\subsection{Der Ewige Jude (El Judío Eterno)}

No podemos concluir el análisis del año 1937, clave para entender la evolución del anticomunismo en el Tercer Reich y en sus aliados -adhesión de Italia al Pacto Antikomintern, intensificación de la propaganda nazi en la Guerra Civil Española o directrices de Goebbels potenciando la lucha contra el comunismo a nivel mundial (Waddington, 2007: 122-140) - sin incluir la exposición Der Ewige Jude. Se inauguró en noviembre de 1937 en el Deutsches Museum de Múnich, ubicación donde ya se había expuesto Große antibolschewistische Schau meses atrás, siendo trasladada después a Viena, Berlín, Dresde y Magdeburgo, ya en junio de 1939. La dirección volvió a recaer en Walter Wüster ya que era la máxima autoridad del Ministerio de Propaganda y del NSDAP en Múnich. Fue arropado por los elementos más radicales y antisemitas del Estado nazi que no escatimó medios y recursos para el éxito de 
este espectáculo. Entre ellos se encontraba el Dr. Wilhelm Ziegler, del Instituto para el Estudio de la Cuestión Judía - una de sus producciones más conocidas fue Die Judenfrage in der modernen Welt (1937)-; el Dr. Wilhelm Grau, del Instituto para la Historia de la Nueva Alemania -entre sus trabajos se incluye Die Juden in der deutsches Geschichte (1937); Erich Uetrecht, director del Archivo del NSDAP; o el periodista y escritor, Hans Diebow, autor de títulos como Die Juden in USA (1939) o Die Rassenfrage (1924), y que se encargará de confeccionar un extenso trabajo sobre esta exposición, tema del que nos ocuparemos en los siguientes párrafos (Diebow, $1397)^{9}$.

Como reflejó el diario Völkischer Beobachter, Der Ewige Jude se desplegó a lo largo de $3.500 \mathrm{~m}^{2}$, en un total de veinte habitaciones en las que, con gestos de denuncia, la utilización de imágenes estereotipadas y la repetición de acusaciones difamatorias ofrecía al espectador "una sencilla visión del mundo del antisemitismo" que se había ido forjando en el sentir popular alemán desde el siglo XIX. Sin embargo, lejos de toda simplicidad, para la elaboración del guion conceptual y teórico de esta exposición, así como de otras muchas, fueron indispensables los trabajos de Johann von Leers -estrecho colaborador de Goebbels, miembro de las $S S$ y su organización dependiente la Rasse und Siedlungshauptamt (Oficina Principal de Raza y Asentamiento)-, como, por ejemplo, Juden sehen Dich an (1933), Blut und Rasse in der Gesetzgebung (1936) o Die Kriminalität des Judentums (1936) (Benz, 2010: 39-40).

En estos espacios se analizaron multitud de temas que tenían a los judíos como protagonistas: los fundamentos biológicos del judaísmo; el papel que ocuparon en la República de Weimar -despectivamente calificado como "El Dorado de los Judíos"-, su presencia preeminente y absorbente, según la terminología entonces empleada, en el Cine, Teatro, Literatura, etc. El lenguaje del odio nazi se articuló mediante numerosas imágenes de empresarios judíos que deberían provocar asco; esquemas compositivos que reflejaban "su degeneración racial" -aparecían a gran tamaño dibujos detallando cómo eran las cabezas, ojos, narices y orejas propias de la raza judía-; los vínculos estrechos entre judaísmo y bolchevismo, y un largo etcétera.

Un análisis pormenorizado revela como en el panel titulado Judenherrschaft se mostraban los rostros a gran tamaño de políticos judíos alemanes participantes en los movimientos revolucionarios de 1918 y 1919 como, por ejemplo, Kurt Eisner, quien organizó la Revolución de Noviembre en Baviera; Eugen Leviné-Nissen, miembro del Partido Comunista alemán y uno de los impulsores de la República Soviética de Baviera; o Erich Mühsam, escritor anarquista que en algunas de sus obras criticó el nazismo y satirizó la figura de Hitler. Con esta fotocomposición se quería poner en la palestra que detrás de las maniobras del bolchevismo internacional siempre se encontraba la raza judía (Benz, 2010: 70). 
Imagen 6 y 7: Diferentes salas de la exposición Der Ewige Jude. A la izquierda panel criticando a destacadas personalidades judías (como Albert Einstein) y a la derecha se explicaba la manera de identificar a los judíos a lo largo de la historia a través de su vestimenta
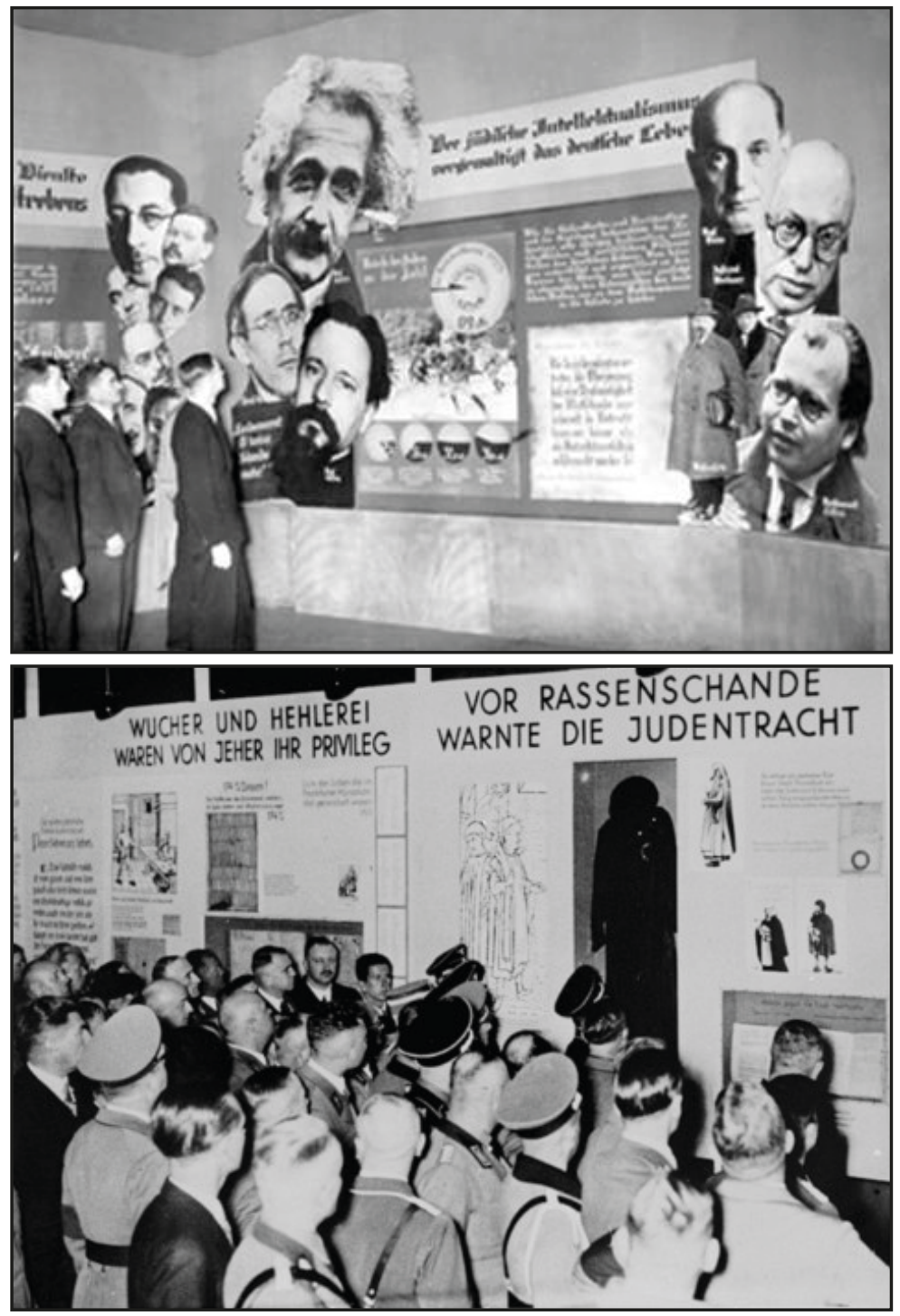

Fuente: Benz, 2010 
Otra sala muy llamativa era aquella donde se criticaban algunos de los mensajes religiosos plasmados en el Talmud. Para darle mayor credibilidad a su mensaje, la propaganda nazi reproducía varios fragmentos muy controvertidos de dicho libro sagrado. Era el caso del Iore Dea 147,5 en el que el ciudadano alemán podía leer sorprendido que "está permitido burlarse de los dioses de los gentiles". Para potenciar el radicalismo religioso judío, seguidamente se plasmaba otra frase en la que se expresaba que "está prohibida la bula a nuestro Dios". Todo este material se posicionaba sobre letras de gran tamaño y en negrita para resaltar su mensaje con la siguiente frase: "Se permite la blasfemia" (Benz, 2010: 101).

Otro panel estuvo compuesto por los carteles publicitarios de decenas de películas de producción judía estrenadas en la Alemania de los años veinte y que se caracterizaban por su temática escabrosa y escandalizadora a los ojos del buen ciudadano germano. Era el caso de títulos como Mädchenhandel (Trata de Blancas); Die Büchse der Pandora (La Caja de Pandora), en la que se trataba el lesbianismo; Alraune, donde una prostituta era inseminada artificialmente con el semen de un ahorcado; o Das Testament der Dr. Mabuse de Fritz Lang, centrada en un demente que planeaba acabar con el orden social mediante constantes actos criminales. Todos estos largometrajes habían sido censurados por las autoridades nazis y fueron utilizadas para mostrar la mente sórdida de los directores y productores de origen judío (Benz, 2010: 107).

Finalizaremos este repaso a los contenidos e imágenes más relevantes de esta exposición deteniéndonos en su última sala Juden entfesseln den Bolschewismus (Los judios desatan el Bolchevismo). En ella se encontraba un enorme retrato de Hitler y las leyes de Núremberg grabadas en mármol. Se complementaban estos símbolos del nacionalsocialismo con los mapas de España, México, Estados Unidos y Francia, cuyo interior estaba formado por recortes de prensa y fotografías que denunciaban la acción del judaísmo internacional dentro de sus fronteras (Benz, 2010: 114).

Para poder entender la totalidad de elementos plasmados en las paredes del Deutsches Museum se editó una breve guía, de 32 páginas, en los que se profundizaba en los paneles más relevantes y que se acompañaba de una breve explicación de cada uno de ellos. Poco tiempo después, todo este material inspiró un libro más extenso, de igual nombre que la exposición, bajo la autoría del citado Hans Diebow (1937). Con un total de 128 páginas y más de 200 fotografías, ponía el énfasis en "la ambición sin mesura y codicia de los judíos del Este de Europa" (16); "lo mal olientes y sucios que eran los ghettos que estaban creando en Berlín" (18); la "falta total de talento en su arte", considerado "primitivo" (51); se ridiculizaba famosos personajes de origen judío como Einstein o Charles Chaplin, llamado "torpe pies planos" (67-68); o la relación que establecían con los "negros" de otros países, "exportando su mundo de perversión a otras razas" (97).

La triste notoriedad que alcanzó este evento a nivel mundial estuvo provocada por los documentales y largometrajes que le acompañaron, y que son considerados como una de las más violentas creaciones de odio contra una colectividad concreta. Ya 
en 1937, durante su celebración en Múnich, se proyectaron fragmentos de películas que posteriormente serían integrados en el documental Juden ohne Maske, dirigido por Walter Bötticher y producido por el Reichspropagandaleitung del NSDAP. En esta producción únicamente aparecían escenas seleccionadas de películas de los años veinte y treinta, como $M$, el vampiro de Düsseldorf de Fritz Lang -sobre un asesino de niñas al que se vinculaba con el pueblo judío- y donde actuaban actores judíos proscritos como Peter Lorre o Fritz Kortner. Se usaron planos que desfiguraban sus rasgos y les hacían parecer ejemplos vivientes de la condición infrahumana a la que estaba adscrita su raza (España, 2002: 95-96).

Habrá que esperar a 1940, en plena guerra mundial, para que se estrenase el largometraje que llevaba el nombre de la exposición antisemita de noviembre de $1937^{10}$. El contexto en el que se produjo su presentación pública difería enormemente de la fecha señalada. En septiembre de 1939, la Alemania nazi había iniciado la invasión de Polonia (Evans, 2009). En 1940, con este país bajo control germano, uno de los objetivos de este dispositivo cinematográfico fue generar una mirada hacia lo judío lo más negativa posible, que garantizara la colaboración de los distintos estratos sociales en los mecanismos de deportación que condujeron al Judenfrei o Judenrein, es decir, la limpieza racial de los territorios ocupados. Sabemos que la población alemana, más allá de los miembros de las SA o de las SS, no se mostró especialmente colaborativa durante los primeros hitos del Holocausto.

Así, tras la Noche de los Cristales Rotos, el aparato propagandístico del Partido Nazi comprendió que era necesario realizar una campaña más exhaustiva que escindiera entre Die Jude, el judío como categoría, y Die Juden, los judíos como individuos singulares, presentes en los distintos estratos de la sociedad y con un avanzado grado de integración en la vida alemana. Pese a los mecanismos de segregación que se habían desatado tras la proclamación de las Leyes de Núremberg, la experiencia del alemán medio no coincidía ni con los estereotipos proclamados por la prensa, ni tenía rastros visibles de exterioridad o de alteridad (Rodríguez Serrano, 2013: 417-418).

La producción de Der Ewige Jude corrió a cargo, también, del NSDAP. La dirección recayó en Fritz Hippler -responsable del Departamento de Cine del Ministerio de Propaganda- autor además del documental de 1939 titulado Feldzug in Polen (Campaña en Polonia) y el guión fue escrito por Eberhard Taubert, miembro también de ese ministerio y conocido por su acentuado antisemitismo. El discurso utilizado viene marcado por la irracionalidad más absoluta que solo busca provocar la nausea en el espectador. El clímax de repugnancia máxima viene dado por la filmación sin truco del degollamiento de varias terneras, (cinco interminables minutos que se extiende del corte 1:02:00 al 1:07:00. Por su innegable crudeza, esta escena encontró oposición en algunos medios, por lo que se decidió hacer una versión especial en la que quedaba eliminada a fin de que pudiera ser vista por mujeres y niños. De esta manera, en el UFA-Palast am Zoo se proyectaban dos sesiones, a las 16:00 horas en versión recortada y a las 18:30 la íntegra. A pesar del esfuerzo promocional y del innegable poder de convicción de las imágenes, la reacción del público fue muy poco entusiasta, por no decir totalmente negativa, y se tuvo que reducir su explotación 
a circuitos no comerciales. Der Ewige Jude fue uno de los grandes fracasos de la propaganda nazi y cerró el ciclo de películas antisemitas, aunque no de exposiciones (España, 2002: 105).

\section{Exposiciones positivas: modernidad y progreso en el Reich}

En 1937, con muchos menos medios y repercusión, pero coetánea a la exposición antisemita, la Sociedad Alemana de Arte de Bettina Feistel-Rohmeder inició una gira por ciudades como Múnich, Stuttgart o Karlsruhe. Era un intento, aunque marginal, por competir con el Partido en materia propagandística y artística. Frente a las sombras del judaísmo y el bolchevismo, se promocionaba la "luz" del verdadero arte del Tercer Reich (Clinefelter, 2005: 92-93). Bajo esta línea constructiva y reivindicativa de las realizaciones y mejoras promovidas por Hitler desde la toma de poder se encontraban las exposiciones Gibt mir vier Jahre Zeit! y Schaffendes Volk.

La primera de ellas, cuyo título en castellano significa "Dame cuatro años", se inspiraba en el discurso dado por Hitler en 1933 en el que proclamó que, en menos de un lustro, Alemania recuperaría el potencial económico y militar perdido tras el Tratado de Versalles (Weinberg, 2005: 276). Sus preparativos se remontan al otoño de 1936, aunque abrió sus puertas en abril de 1937, en un momento especialmente delicado por la diplomacia nazi a causa de la polémica que suscitó a nivel internacional el bombardeo de Guernica por la Legión Cóndor (Southworth, 2013). La organización técnica y de contenidos fue llevada a cabo por Wilhelm Haeger, director de Personal del Departamento de Propaganda y, en estas fechas, responsable de la División II del Ministerio de Propaganda; y Wolfgang Willrich, famoso escritor y dibujante nazi. El cartel publicitario con el que se anunció este evento mostraba a Hitler en el centro de un gran paisaje industrial -símbolo de la recuperación económica del país-, bajo un ambiente de color alba, anticipo de la sangre y fuego que conllevaría la Segunda Guerra Mundial.

No se escatimaron recursos económicos y logísticos de ningún tipo, quedando instalada la muestra en la Berliner Funkturm (la Torre de la Radio). A lo largo de sus dos meses de duración -del 30 de abril al 20 de junio- fue visitada por cerca de un millón y medio de personas quienes, en un espacio gigantesco de más de $38.000 \mathrm{~m}^{2}$, pudieron contemplar de forma sorprendente y monumental los logros realizados por el partido nazi desde la asunción del poder en 1933. El ciudadano alemán quedaba sorprendido ante los enormes fotomontajes -algunos de ellos de 18 metros de altura en los que Hitler era "arropado" por los Trabajadores y la Juventud- sobre la revitalización del país y la instalación de aviones, tanques, cañones, submarinos, etc. con los que se había dotado al Ejército en los últimos años (Zuschlag, 1995:169-172). 
Imagen 8 y 9. Exposición Gibt mir vier Jahre Zeit A la izquierda cartel promocional y a la derecha fotomontaje junto a armas de la Nueva Alemania

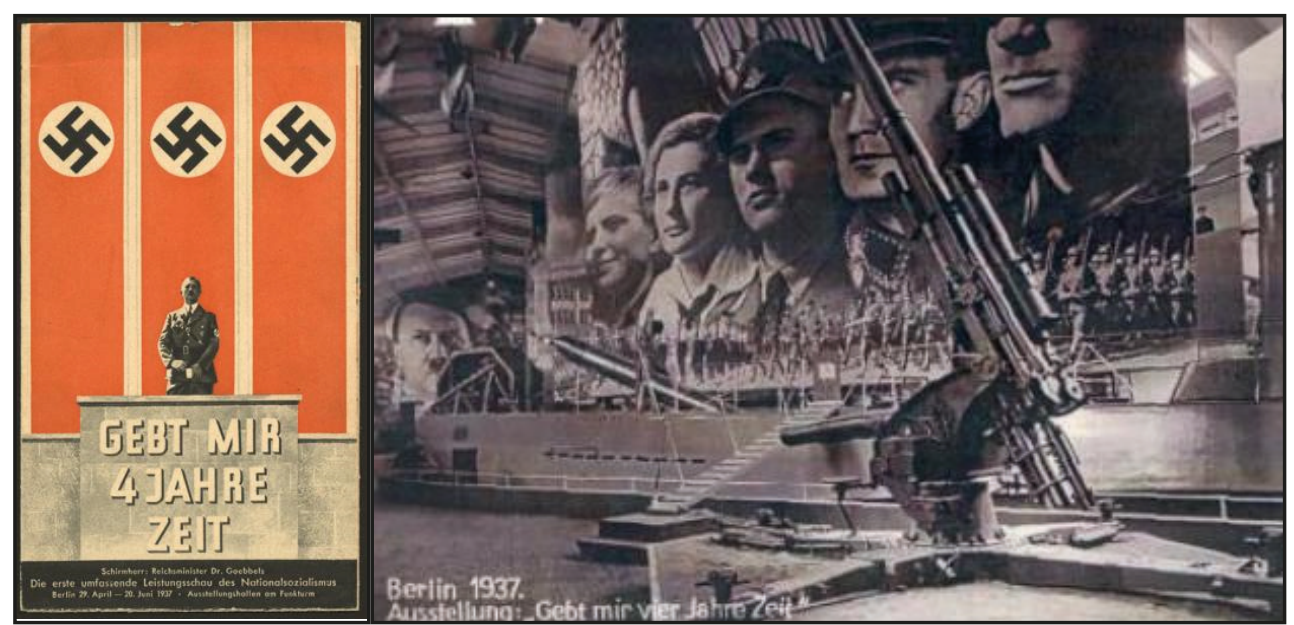

Fuente: Gibt mir vier Jahre Zeit 1937

Por su parte, la Reichsausstellung Schaffendes Volk (Exposición del Reich sobre el Pueblo Trabajador) eligió a Düsseldorf para proyectar ante el ciudadano las virtudes de la nueva economía alemana (Schäfers, 2001). Para hacer atractiva esta idea se creó un espacio totalmente nuevo dentro de la ciudad que englobaba enormes parques, jardines, recintos feriales, plazas, etc. En estrecha relación con la exposición anteriormente citada, se quería celebrar la recuperación de dicha urbe, aquejada por una fuerte depresión y una elevada tasa de desempleo durante los años de la República de Weimar. Y qué mejor manera para celebrar este resurgir económico que construyendo, en este atractivo punto al lado del Rin, multitud de puestos y pabellones donde tenían cabida los numerosos adelantos cotidianos del país.

Uno de los edificios más destacados fue el que instaló la compañía Henkel, centrada en numerosos campos como el cuidado del hogar, artículos de higiene personal o bienes de consumo. Era todo un símbolo de la autarquía promovida por el Estado que, a través de actos como el presente, quería impulsar la figura del consumidor doméstico. Aquel que con su esfuerzo y demanda de productos nacionales contribuía a la revitalización económica, higiénica y racial de Alemania. Fue visitada por más de siete millones de personas, entre las que figuraron Hitler, Rudolf Hess, Hermman Göring, Albert Speer, Goebbels, o ilustres personajes extranjeros como el príncipe Chichibu (hermano del emperador de Japón) o el duque de Windsor (Wiesen, 2011: 94-97). 
Imagen 10 y 11. Diferentes imágenes promocionales de la exposición Schaffendes Volk
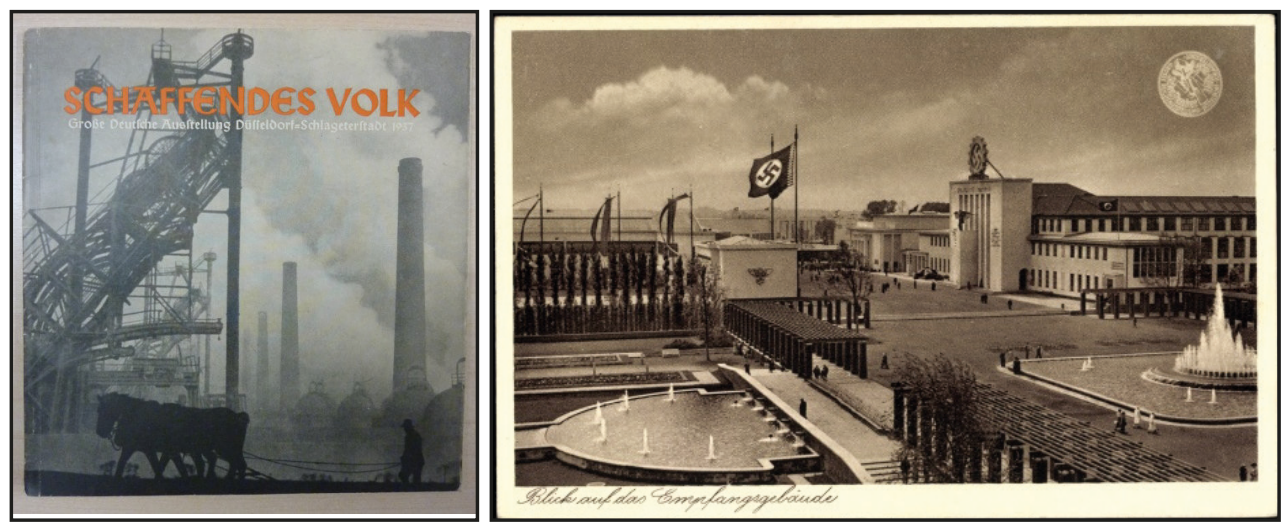

Fuente: Grosse Reichs-Ausstellung Schaffendes Volk (1937).

\section{Conclusiones}

Las exposiciones propagandísticas impulsadas desde los años treinta por Goebbels y su equipo de ideólogos forman parte de un complejo mecanismo de socialización violenta, tendente a la denuncia del otro y su marginalidad-eliminación del campo político y social del Tercer Reich.

El arte contemporáneo y la propaganda se han caracterizado, desde sus inicios, por una fuerte carga de violencia visual. Sin embargo, la simple repetición de imágenes de violencia no cumple su finalidad si no va acompañada de otro elemento igualmente importante. Exige la aceptación y asimilación de una ideología que justifique o legitime el contenido de tales representaciones. En esta línea, Richard Rhodes fue uno de los primeros historiadores que buscó una respuesta a la violencia presente en el Tercer Reich desde el campo de la criminología (2003: 44-57). Para ello se inspiró en la revolucionaria teoría de Lonnie Athens, conocida como Proceso de socialización violenta, que se dividía en cuatro etapas secuenciales. Cada una de ellas debía ser completamente experimentada antes de que el sujeto avanzase hacia la siguiente. Un proceso que podía ocurrir como un cataclismo en un corto espacio de tiempo o a través de un largo periodo de años. Estas cuatro fases son: brutalización, beligerancia, actuación violenta y virulencia. Aunque esta teoría fue elaborada para dar una explicación al comportamiento violento de los funcionarios de los cuerpos de seguridad del Estado nazi así como de los miembros del estamento militar, algunas de sus conclusiones -especialmente las de la primera fase- pueden extrapolarse al mensaje y mecanismos empleados por la maquinaria propagandística del Tercer Reich para despertar el odio/violencia que se encuentra en la base de las futuras acciones deleznables de la sociedad alemana. 
En la fase conocida como brutalización se combinaban tres experiencias significativas: la subyugación violenta, la aterrorización personal y, la que más nos interesa, el adoctrinamiento violento. En las tesis originales de Athens el sujeto era conducido a esa "brutalización" por algún miembro de su grupo primario -un familiar normalmente- pero, sin negar la importancia de estos vínculos en ese proceso de socialización violenta, los estados totalitarios procuraron intervenir en la misma a través de la cultura, la propaganda y la educación (Athens, 1992: 46-49; y Athens y Ulmer, 2003: 1-42). En definitiva, un adoctrinamiento que impedía que el individuo permaneciera pasivo y en el que los artistas podían jugar, y así lo hicieron, un papel esencial a la hora de exacerbar los prejuicios frente a las ideas comunistas o a colectivos como los judíos.

Este agente adoctrinador, que nosotros equiparamos al Ministerio de Propaganda o a las diversas instituciones culturales y educativas del Reich, utilizaba diferentes técnicas para inocular esta violencia. Así, un mecanismo muy poderoso será la sublimación de la propia causa a partir de un relato que incita a odiar al otro por las atrocidades cometidas en el pasado -sean estas reales o no- así como por las que podría llegar a cometer en el futuro. Era el caso de las continuas apelaciones a la Dolchstosslegende (puñalada por la espalda) de la propaganda nazi, en concreto a determinados elementos, judíos y partidos de izquierda, tras la derrota alemana en la Primera Guerra Mundial (Deist and Feuchtwanger, 1996).

En esta primera categoría de la violencia y el odio -la brutalización y su adoctrinamiento- se ubicaron el Arte y la cultura nazi. Los propagandistas o artistas, entre otros gremios, con sus escritos, pinceles o lápices fueron uno de los eslabones de este embrutecimiento de la sociedad. Con sus producciones contribuyeron a exacerbar una serie de prejuicios y obsesiones contra los judíos y los comunistas, cumpliendo al pie de la letra las indicaciones de los organismos estatales responsables de la cultura y el adoctrinamiento de la sociedad.

Todas las exposiciones nazis asimilaron una fuerte carga de violencia visual, de rechazo, de odio, fruto de un metódico y bien estudiado plan de exaltación de los valores arios frente a los enemigos políticos y raciales que constituían un mismo ente para las élites del NSDAP (Mosse, 2005). En todas estas proyecciones ideológicas y propagandísticas afloraba un sentimiento claro, el deseo de reescribir la historia según sus intereses. Si el marxismo había intentado interpretar la historia del mundo en términos de lucha de clases, el nazismo presentó al pueblo alemán como víctima de una conspiración judía responsable de los grandes males del país desde tiempo inmemorial. Toda esta literatura, así como las tesis de los más destacados ideólogos del Ministerio de Goebbels, tomaron cuerpo en las exposiciones de propaganda negativa que, como se ha puesto de manifiesto, se impulsaron desde 1936, coincidiendo con el inicio de la Guerra Civil Española. Se acude a este marbete porque los elementos que en ella defendieron, teñidos todos del color del odio, solo encontraban su razón de ser y lograban el impacto público que pretendían mediante la técnica de la confrontación y de la antítesis con todo aquello que rezumase judaísmo y bolchevismo. Mecanismo mucho más efectivo y efectista que las exhibiciones de corte positivo. 


\section{Referencias bibliográficas}

ATHENS, L. H. (1992). The creation of dangerous violent criminals. Urbana and Chicago: University of Illinois Press.

ATHENS, L. H. y ULMER, J. (2003). Violent Acts and Violentization: assessing, applying and developing Lonnie Athen's Theories. Oxford: Elsevier Science.

BALDAUF, H. (1938) Christen im spanischen Sturm. Tatsachenberichte zur Verfolgung der Kirche in Spanien. Saarbrücken: Saarbrücker Druckerei und Verlag AG.

BENZ, W. (2010). Der Ewige Jude. Metaphern und Methoden nationalsozialistischer Propaganda. Berlin: Metropol.

BERTHIER, N. y SÁNCHEZ-BIOSCA, V. (2012). Retóricas del miedo. Imágenes de la Guerra Civil Española. Madrid: Collection de la Casa de Velázquez.

BOWEN, W. H (2000). Spaniards and Nazi Germany: collaboration in the New Order. Columbia: University of Missouri Press.

BURKE, P. (2001). Visto y no visto. El uso de la imagen como documento histórico. Barcelona: Crítica.

CLINEFELTER, J. L. (2005). Artists for the Reich: Culture and Race from Weimar to Nazy Germany. Oxford: Berg Publishers.

Das Rotbuch über Spanien (1937). Berlin: Nibelungen Verlag.

DEIST, W. and FEUCHTWANGER, E.J. (1996). "The Military Collapse of the German Empire. The reality behind the Stab-in-the-back Myth". En War in History, vol 3, 2, pp. 186-207.

Der Bolschewismus: grosse antibolschewistische Schau im "Bibliotheksbau” des Deutschen Museums (1936). München: NSDAP

DIEBOW, H. (1924). Die Rassenfrage. Rassenkunde, Vererbungslehre und Rassenhygiene. Berlin: Arbeitszentrale f. Völkische Sprechabende.

DIEBOW, H. (1937). Der Ewige Jude. München: Eher. Disponible en www.calvin. edu/academic/cas/gpa/diebow [acceso el 12 de mayo de 2014].

DIEBOW, H. (1939). Die Juden in USA. Berlin: Eher.

ESKILSSON, S. (2009). "Ein Gemälde geht ins Exil. Auf den Spuren der «Kreuzabnahme» von Max Beckmann”. En FLECKNER, U. (ed). Das verfemte Meisterwerk: Schicksalswege moderner Kunst im Dritten Reich. Berlin: Akademie Verlag, pp. $105-136$

ESPAÑA, R. (2002). El cine de Goebbels. Barcelona: Ariel.

EVANS, R. (2005). The third Reich in Power. New York: Penguin Press.

EVANS, R. (2009). The third Reich at War. New York: Penguin Press.

EYKMAN, C. (1992). "The Spanish Civil War in German Publications during the Nazi Years". En COSTA, L. et al. German and International Perspectives on the Spanish Civil War: the Aesthetics of Partisanship. Columbia: Candem House, pp. 166-178.

FREUD, S. (1991). Psicología de las masas. Madrid: Alianza Editorial.

Gibt mir vier Jahre Zeit (1937). Berlin: s.e.

GOEBBELS, J. (1937). La Verdad sobre España. Discurso pronunciado en Núremberg en el Congreso Nacional del Partido en 1937. Berlín: M. Müller \& Sohn, S.A. 
GRAU, W. (1937). Die Judenfrage in der deutschen Geschichte. Leipzig: Teubner. Grosse Reichs-Ausstellung Schaffendes Volk (1937). Düsseldorf: Dresdner Bank.

Große antibolschewistische Ausstellung. (1937). Berlin: Verlag für Kultur. Wirtschaftswerbung Daenell \& co. Disponible, en su mayor parte, en www.calvin.edu/ academic/cas/gpa/anti-bolshevism.htm [Acceso el 12 de mayo de 2014].

HERF, J. (2006). The Jewish Enemy. Nazi propaganda during World War II and the Holocaust. Harvard University Press.

HOBSBAWM, E. (1995). "Foreword". En ADES, D. and BENTON, T. Art and Power. Europe under the Dictators 1930-1945. London: Hayward Gallery, pp. $11-15$.

HURTADO LAMAS, E. (2013). "El lugar de la imagen. Una aproximación al giro de la imagen y el marco de los estudios visuales". En ORTEGA, T.M. y ARCO, M. (eds.). XI Congreso de la Asociación de Historia Contemporánea. Granada: Comares

KIVELITZ, C. (1999). Die Propagandaausstellung in europäischen Diktaturen. Konfrontation und vergleich: Nationalsozialismus in Deutschland, Faschismus in Italien und die UdSSR der Stalinzeit. Bochum: Verlag.

LEERS, J. Von (1933). Juden sehen Dich an. Berlin: NS.-Druck u. Verlag.

LEERS, J. Von (1936). Blut und Rasse in der Gesetzgebung. München: J.F. Lehmanns Verlag

LEERS, J. Von (1936). Die Kriminalität des Judentums. Berlin: Deutscher Rechts-Verlag

Los protocolos de los sabios de Sión (1920). S.l.: Publicaciones Medio-Oriente

MAYOR FERRÁNDIZ, T. M (2011). "John Heartfield, un artista antinazi”. En Revista de Claseshistoria. Publicación digital de Historia y Ciencias Sociales, 4. Disponible en http://www.claseshistoria.com/revista/2011/articulos/mayor-heartfield.pdf [acceso el 12 de mayo de 2014]

MCDOUGALL, W. (1920). The Group Mind. Cambridge: Cambridge University Press.

MONTEATH, P. and ELKE, N. (1986). Zur Spanienkriegsliteratur. Die Literatur des Dritten Reiches Zum Spanischen Bürgerkrieg. Frankfurt am Main: Verlag Peter Lang.

MONTEATH, P. and ELKE, N. (1994). Writing the Good Fight: Political Commitment in the International Literature of the Spanish Civil War. Westport, CT: Greenwood Press.

MORENO CANTANO, A.C. (2008). Los Servicios de Prensa Extranjera en el primer franquismo. Tesis, Universidad de Alcalá, inédita.

MOSSE, G.L. (2005). La nacionalización de las masas. Madrid, Marcial Pons.

REDDY, W.M. (2001). The Navigation of Feeling: A Framework for the History of Emotions. New York: Cambridge University Press.

RHODES, R. (2003). Amos de la muerte. Los SS Einsatzgruppen y el origen del Holocausto. Barcelona: Seix Barral.

RODRÍGUEZ SERRANO, A. (2013). "El preludio del Holocausto. La configuración del espectador en El Judio Eterno (Der Ewige Jude, Fritz Hippler, 1940)". En 
PÉREZ PERUCHA, J. y RUBIO ALCOVER, A. (eds.): De cimientos y contrafuertes. El papel de los géneros en el cine español. Actas del III Congreso Internacional del Departamento de Comunicación Audiovisual y Publicidad (UAV/ EHU), pp. 416-427.

ROHR, I. (2007). The Spanish Right and the Jews, 1898-1945: Antisemitism and Opportunism. Eastboune: Sussex Academic Press.

ROSENWEIN, B.H. (2010). "Problems and Methods in the History of Emotions". En Passions in contexts. International Journal for the History and Theory of Emotions, ${ }^{\circ} 1$. http://www.passionsincontext.de/index.php?id=557 [acceso el 12 de mayo de 2014].

SADOUL, J. (1920). Notes sur la révolution bolchevique. Paris: Éditions de la Sirène. SCHÄFERS, S. (2001). Vom Werkbund zum Vierjahresplan. Die Ausstellung "Schaffendes Volk”, Düsseldorf 1937. Düsseldorf: Droste.

SCHUSTER, P.K et al. (1988). Die "Kunststadt" München 1937. Nationalsozialismus und "entartete Kunst". München: Prestel-Verlag, 1988.

SMITH, W. D. (1989). The ideological origins of nazi imperialism. Oxford: Oxford University Press.

SOUTHWORTH, H. R. (2013). La destrucción de Guernica. Periodismo, diplomacia, propaganda e historia. Granada: Comares.

STERNBERG, R.J. (ed) (2005). The Psychology of hate. Washington, D.C.: American Psychological Association.

STERNBERG, R.J. and STERNBERG, K. (2008). The Nature of Hate. Cambridge: Cambridge University Press.

VON ZUBER, B. (2009). "Welche Ausstellung Münscher Schülerinnen und Schüler, 1933-1945, Klassenweise besuchten". En Einsichten und Perspektiven. Bayrische Zeischrift für Politik und Geschichte, 2, pp. 128-151.

WADDINGTON, L. (2007). Hitler's Crusade. Bolshevism and the myth of the International Jewish conspiracy. London - New York: Tauris Academic Studies.

WEINBERG, G. L. (2005). Hitler's Foreign Policy. The road to World War II. New York: Enigma Books.

WEINREICH, M. (1999). Hitler's Professors. The part of the scholarship in Germany's Crimes against the Jewish people.New Haven: Yale University Press.

WELCH, D. (2002). The Third Reich. Politics and Propaganda. Abingdon: Routledge.

WIESEN, S. J. (2011). Creating the Nazi Martketplace: commerce and consumption in the Third Reich. New York: Cambrigde University Press.

WILLIAMS, K. (2007). "Kultur-Terror. The composite Monster in Nazi Visual Propaganda". En SCOTT, N. (ed.). Monsters and the Monstrous. Myths and Metaphors of Enduring Evil. Amsterdam: Editions Rodopi B.V, pp. 81-102.

ZARAGOZA BERNAL, J. M. (2013). "Historia de las emociones: una corriente historiográfica en expansión”. En Asclepio, 65 (1). Disponible en http://asclepio. revistas.csic.es/index.php/asclepio/article/view/547/572 [acceso el 12 de mayo de 2014]. 


\section{ZIEGLER W. (1937). Judenfrage in der modernen Welt. Berlin: Junker und Dünn- haupt. \\ ZUSCHLAG, C. (1995). "Entartete Kunst”:Ausstellungsstrategien im Nazi-Deuts- chland. Worms: Werner.}

\section{Notas}

1 Este artículo es una breve presentación de una investigación de mayor calado, en estos momentos en fase de elaboración, en la que abordamos el origen, puesta en marcha y contexto histórico-político-artístico de las exposiciones de signo antimarxista desarrolladas en la Europa del Eje -Alemania nazi, Francia de Vichy, Rumania de Antonescu y la España franquista- durante la Segunda Guerra Mundial. Matizar, igualmente, que en este texto únicamente se analizan las exposiciones de carácter propagandístico que tuvieron lugar en los años treinta, omitiendo también las de signo artístico como Das Entartete Kunst y Exposition International des Arts et des Techniques dans la Vie Moderne, ambas de 1937.

2 Miembro del Departamento de Propaganda del Gauleiter de Múnich. Organizó diferentes exposiciones itinerantes como Der ewige Jude, a la cual se hace también referencia en este artículo. Tras ocupar la dirección general de la Asociación germano-italiana, posteriormente, pasó a formar parte del Ministerio de Exteriores de Ribbentrop, donde encabezó la rama bávara de la Asociación de relaciones culturales alemanas en el extranjero. También fue Cónsul General en Milán y responsable del Departamento de la Oficina de Información Extranjera (Von Zuber, 2009: 128-151).

3 Sobre este tema existe una abundante literatura como Monteath y Elke (1986); o Eykman (1992:166178).

4 Véase la reseña aparecida en $A B C$, el 26 de enero de 1937.

5 Funcionario del Antikomintern, ayudó a la creación de la Entente Internationale Anticommuniste (EIA). Estuvo en estrecho contacto con Aubert en Ginebra y con el movimiento Rex de Leon Degrelle en Bélgica. También contribuyó a la constitución de diferentes oficinas anticomunistas en capitales de América Latina, como Montevideo. En 1939 elaboró el Memorándum sobre la interferencia del bolchevismo y las democracias en España. Sobre esta desconocida y relevante figura propagandística véase Waddington (2007: 102-104).

6 Fue Jefe de la Unidad de Derecho Constitucional e Internacional del Antikomintern. En 1937 escribió la obra Völker-Recht gegen Bolschewismus (Derecho Internacional contra el Bolchevismo).

7 Archivo General de la Administración (en adelante, AGA), Presidencia, Secretaría General del Movimiento (en adelante, SGM), caja 20.891. "Escrito de Luis Sánchez Maspons a Joaquín Rodríguez de Gortazar, Jefe de Intercambio y Propaganda Exterior", 7 de diciembre de 1937.

8 AGA, Presidencia, SGM, caja 20.891, 22 de mayo de 1937. La cursiva es nuestra.

9 Para una visión general sobre las instituciones mencionadas véase Max Weinreich (1999).

10 Este título encajaba en la calificada como "Trilogía del odio", junto a Jud Süss (El Judío Suss) y Die Rotschschilds. La primera de estas piezas fue dirigida por Veit Harlan, uno de los directores estrella del cine nazi y que al acabar la guerra fue procesado por crímenes contra la Humanidad. Esta película batió récords de taquilla en el Reich y en los países satélites. En España, aparte de pases semiprivados, no tuvo distribución comercial (España, 2002: 94-96). 


\section{Los autores}

Antonio César Moreno Cantano. Doctor en Historia Contemporánea por la Universidad de Alcalá de Henares (2008). Miembro del grupo de investigación CEFID y GREF, adscritos a la Universidad Autónoma de Barcelona; del grupo de investigación Catolicismo y laicismo en la España del siglo XX, vinculado a la Universidad de Alcalá, y al grupo Estudios del Tiempo Presente de la Universidad de Almería. Ha participado en diferentes congresos sobre la dictadura franquista y ha publicado numerosos artículos sobre la propaganda interior y exterior de la España franquista durante la Guerra Civil y la Segunda Guerra Mundial. Ha coordinado en Trea una trilogía sobre las culturas bélicas y la propaganda en España entre 1936 y 1945. Su última publicación ha sido la obra colectiva Otra Iglesia. Clero disidente durante la Segunda República y la Guerra Civil.

Misael Arturo López Zapico. Licenciado con grado en Historia por la Universidad de Oviedo con premio fin de carrera y premio extraordinario de licenciatura y Doctor por la Universidad de Huelva con premio extraordinario de doctorado en Arte y Humanidades. Ha sido profesor asociado en las Universidades de Oviedo y Murcia y ha realizado estancias como investigador visitante en SUNY New Paltz, UMASS at Amherst, y University of Leeds. En la actualidad es Profesor-tutor del centro asociado de la UNED en Asturias. 